\title{
Pre-service Special Education Teachers Acceptance and Use of ICT: A Structural Equation Model
}

\author{
Sabiha Yeni ${ }^{1}$, Zeynep Gecu-Parmaksiz ${ }^{1}$ \\ ${ }^{1}$ Department of Computer Education and Instructional Technology, Yildiz Technical University, Istanbul, Turkey \\ Correspondence: Sabiha Yeni, Department of Computer Education and Instructional Technology, Yildiz Technical \\ University, Istanbul, Turkey.
}

Received: October 18, 2016

doi:10.11114/jets.v4i12.1929
Online Published: November 11, 2016

URL: http://dx.doi.org/10.11114/jets.v4i12.1929

\begin{abstract}
Information and communication technology (ICT) supported education helps the individuals with special educational needs to take their attention to the course content and to concentrate their attention on the task they need to perform. The mechanical advantages of ICT tools make them attractive for individuals with special educational needs. If special education teachers integrate technological tools and innovative instructional methods into their classes properly, they can use strong tools for communication with individuals with special educational needs and also present different types of vocational, educational and enjoyable activities. The effective and correct use of technology in the lessons is related to special education professionals' qualifications in ICT supported education and ICT usage frequency in their classes and daily lives. The aim of this research was to examine pre-service special education teachers' acceptance and usage frequency of technology in their classes and daily lives. This research analyzed the Technology Acceptance Model (TAM) in order to determine the factors that affect pre-service special education teachers' ICT acceptance and usage decisions. To examine these factors, a Structural Equation Model (SEM) was used. According to findings, special education teachers' perceptions of usefulness (PU) of ICT, as well as opinions of people (SN) they care about regarding use of technology, shape their behavioral intentions (BI) towards ICT. In addition, opinions of people (SN) they care about regarding use of technology predict their perceptions of usefulness (PU) of these technologies.
\end{abstract}

Keywords: special education, pre-service teachers, technology acceptance model, information and communication technology, structural equation model

\section{Introduction}

\subsection{Information and Communication Technologies in Special Education}

Technology is one of the practical ways to improve education for people. With the help of technology, new learning and teaching methods could be produced by professionals (Bertini \& Kimani, 2003) and individuals with special needs find opportunity to try simulations, basic drill and practice, communication or exploratory activities (Edwards, Blackhurst \& Koorland, 1995). Besides, one of the benefits of technology usage in special education is improving higher order thinking skills of individuals by providing meaningful learning experiences. Integrating technology successfully into educational environment can be useful for individuals with special educational needs (Martin, 2004).

ICT supported education helps special individuals to take their attention to the course content and to concentrate their attention on the task they need to perform (Fernández-López, Rodríguez-Fórtiz, Rodríguez-Almendros \& Martínez-Segura, 2013). Some of the mechanical advantages of ICT tools can be favorite for special individuals' education by virtue of their attributes such as storage and usage of large amount of data, providing visual and audio material, etc. (Yee, 2012).

\subsection{Technology supported Instruction with Special Education Teachers}

If special education professionals integrate technological tools and innovative instructional approaches into their lessons properly, they can attain strong tools for communication with special individuals and also present different types of vocational, educational and enjoyable activities (Nam, Bahn \& Lee, 2013). Special education professionals' qualifications in ICT supported education and ICT usage frequency in their lessons and daily lives are related to the effective and correct use of technology in the lessons (Flanagan, Bouck \& Richardson, 2013). 
Teachers stated that they faced some problems such as cost, usability, lack of experience while using assistive technology (AT) (Flanagan et al., 2013). Teacher had limited information about using AT. Special education teacher may have had AT coursework during their undergraduate or graduate education, besides they can attend workshops or seminars for their professional development to enrich their instruction with AT (Derer, Polsgrove \& Rieth, 1996; Lee \& Vega, 2005; Ludlow, 2001; Michaels \& McDermott, 2003 as cited in Flanagan et al., 2013). Moreover, high purchase and upgrade prices are other problems for teachers while using technology. Usability is another problem that teachers faced with, usable tools make easier for them to use technology in special education.

In their studies Nam et al. (2013) tested the relationships among fundamental elements (facilitating condition, perceived ease of use, computer self-efficacy, result demonstrability, perceived usefulness, and behavioral intention) of AT acceptance. The results of the study supported the effects hypothesized in conceptual model of AT acceptance. According to the results the significant element that was affecting AT usage was perceived usefulness.

\subsection{Technology Acceptance Model}

Research model based on Technology Acceptance Model (TAM) was designed by Davis (1989). The aim of the TAM was to explain theoretically the determinants factors of acceptance of computer and be efficient to make explanation for wide range of users' behaviors. The researchers can prefer this model both estimate users' behaviors and make theoretical explanations about technology acceptance. Therefore, TAM guides researchers to identify reasons for a system that was unacceptable and to assist about corrective interventions (Davis, 1989).

\subsection{The Elements of Technology Acceptance Model}

Behavioral intention (BI) is a measurement of degree of person's engaging in a specified behavior. BI can be explained as an individual's presence for acting a behavior. TAM asserted that it determines individual's acceptance or rejection to use of information technology, in other words it states that behavioral intention of individual is the primary factor that determine an individual's actual use (Hu, Clark \& Ma, 2003; Teo, 2011).

Perceived Usefulness (PU) is a positive or negative idea about performance increase in users' jobs that they got after using technology (Davis, 1989). The idea of not waiting in a line can be given as an example of tax payer who pays taxes by online without going tax office.

Perceived Ease of Use (PEU) is a degree to which an individual's beliefs about ease of using particular technology and learning without additional effort. If individuals think that new technology is easy to use, their behavioral intention towards using technology becomes positive. The studies showed that PEU had indirect effect on PU (Davis, 1989). For example, two graphic editors are similar in terms of perceived ease of use; if one of them produces higher quality of graphics than other editor, previous one should be accepted as more useful (Davis, 1989).

Subjective Norm (SN) is a "perceived social pressure to perform or not to perform a behavior" (Hu, Clark \& Ma, 2003; $\mathrm{Ma}$, Anderson \& Streith, 2005). Individuals can perform behaviors with respect to the decisions of people around them (Fishbein ve Azjen, 1975).

\subsection{The Purpose of the Study}

The purpose of this research was to determine pre-service special education teachers' acceptance and usage frequency of technology in their daily lives and lessons. This research analyzed the TAM in order to determine the factors that affect pre-service special education teachers' ICT acceptance and usage decisions. This research examined pre-service teachers' perceived usefulness (PU), perceived ease of use (PEU), behavioral intention (BI) and subjective norm on using ICT tools.

\subsection{Hypothesis}

The general structural model, which included behavioral intention, perceived usefulness, perceived ease of use and subjective norm on technology acceptance of pre-service special education teachers, was developed based on the TAM. Research model was shown in Figure 1.

H1:Pre-service special education teachers' perceived ease of use of ICT tools affects their perceived usefulness of ICT tools.

H2:Pre-service special education teachers' perceived ease of use of ICT tools affects their behavioral intention to use ICT tools.

H3:Pre-service special education teachers' perceived usefulness of ICT tools affects their behavioral intention to use ICT tools.

H4:Pre-service special education teachers' subjective norm on ICT tools affects their perceived usefulness of ICT tools.

H5:Pre-service special education teachers' subjective norm on ICT tools affects their behavioral intention to use ICT tools. 


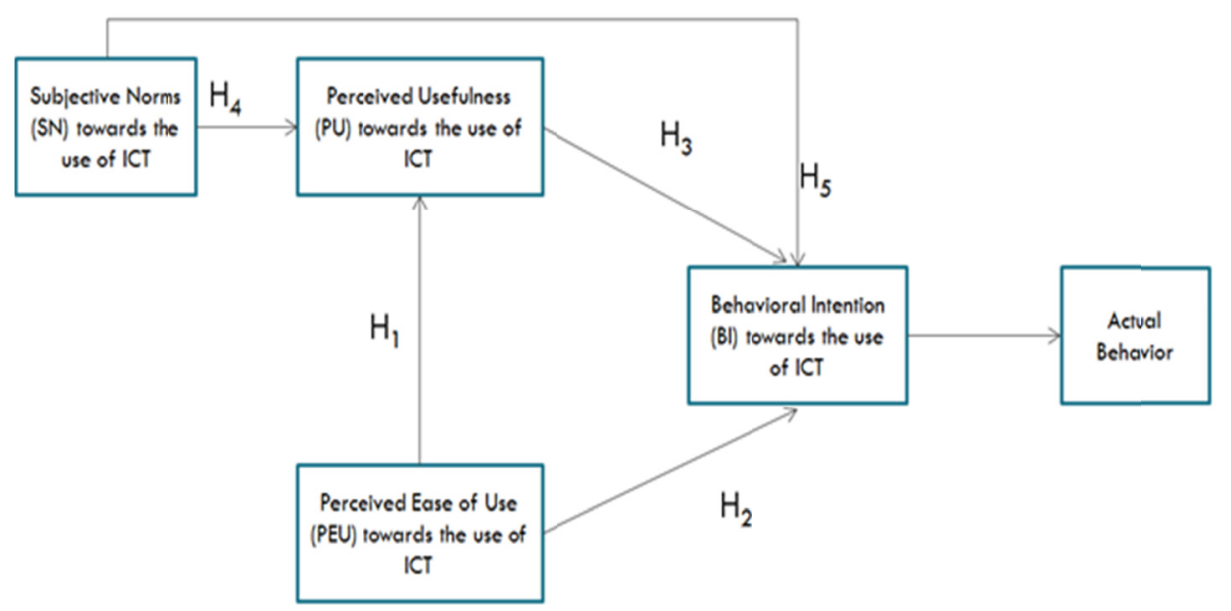

Figure 1. TAM Diagram

\section{Method}

TAM formed the basic framework of this study conducted to identify the factors that affect acceptance and usage of technology by pre-service special education teachers. To examine these factors, a Structural Equation Model (SEM) was used. SEM is a method used to test the relationship between observed and latent variables (Kline, 2005). It is frequently used to test theories because it allows conducting multiple analyses at once, takes measurement errors into account, and facilitates analysis of mediation effects (Kline 2005; Teo, 2009). First, the process of questionnaire development for data collection is explained followed by testing of the hypotheses and a discussion of results.

\subsection{Sampling Procedures}

The universe of the study consists of pre-service teachers attending the special education teaching departments of universities. The sample consisted of students attending Marmara University's Department of Special Education. To examine construct validity of the scale for technology acceptance model, an Exploratory Factor Analysis (EFA) was conducted. A rule of thumb regarding sample size in EFA is that there should be at least 5 subjects per item (Hair, Black, Babin and Anderson, 2005). Given that the TAM scale in this study has 20 items, a sample size of 100 should be sufficient. However, to deal with potential loss of data, the scale was administered to 208 students of Marmara University's Department of Special Education. The age of participants varied between 17 and 28, and the mean age was $21.59 \%$ of the participants (n: 123 ) were female and $41 \%$ were male (n: 85 ). $20 \%$ of the participants were first year students, $30 \%$ were second year students, $30 \%$ were third year students, and $20 \%$ were fourth year students. $67 \%$ of the participants were day students, and 33\% were evening students. Before administering the measurement tool, the purpose of the study was explained to pre-service teachers, and they were informed that they could refuse to participate at any stage of the study or retract their answers. There was no time limit for filling out the forms. Forms were filled out in approximately 20 minutes.

\subsection{Data Collection Tool and Development of the Scale}

The data collection tool used in the study consisted of two main parts. (a) The first part contained personal and professional questions on the gender and age of the participants, the classes they attend, ownership of ICT tools, duration of use, whether they attended ICT courses before, and whether they developed any digital materials. (b) The second part contained a total of 20 items on perceived usefulness ( 6 items), perceived ease of use (6 items), behavioral intention (5 items) and subjective norms ( 3 items). Items on the scale were selected from previous studies on the subject, and from question sets with high reliability figures. Items in this part were 5-point Likert type items.

Table 1. Sources of the Items Used in the Scale

\begin{tabular}{ll}
\hline Factors & Adapted Studies \\
\hline Perceived Usefulness (PU) & Davis (1989) \\
Perceived Ease of Use (PEU) & Davis (1989) \\
Behavioral Intention (BI) & Hu, Clark \& Ma (2003) \\
Subjective Norms (SN) & Hu, Clark \& Ma (2003) \\
\hline
\end{tabular}

Table 1 presents a list of the scale's factors and studies that were consulted when preparing the scale. Items in the scale about perceived usefulness and perceived ease of use were adapted from a question set that was originally used by Davis (1989) and had the high reliability figure of 0.93 . Items on behavioral intention and subjective norms were adapted from questions used by Hu, Clark and Ma (2003). 
Cronbach's alpha internal consistency coefficients were calculated to find out how reliable the data would be. As Table 2 shows, all variables had moderate or high levels of reliability, with reliability coefficients equal to or greater than 0.80 .

Table 2. Reliability Coefficients

\begin{tabular}{lll}
\hline Factors & Number of Factors & Cronbach's Alpha Reliability Coefficients \\
\hline Perceived Ease of Use (PEU) & 6 & .874 \\
Perceived Usefulness (PU) & 6 & .923 \\
Subjective Norms (SN) & 3 & .800 \\
Behavioral Intention (BI) & 5 & .933 \\
\hline
\end{tabular}

\section{Results}

\subsection{Participants' Experience with ICT Tools}

Table 3 reports the ICT tools owned by participants of the study. Table 3 shows that almost all (94\%) participants own smartphones, $88,5 \%$ have internet access, and 75,5\% own computers. Only 2 participants (1\%) said that they did not use ICT tools. Projectors $(3,4 \%)$, scanners $(9,1 \%)$ and printers $(12 \%)$ are among the least owned ICT tools.

Table 3. ICT tools owned

\begin{tabular}{lll}
\hline Devices & Frequency & $\%$ \\
\hline Smartphone & 196 & 94,2 \\
Internet & 184 & 88,5 \\
Computer & 157 & 75,5 \\
Television & 117 & 56,3 \\
Tablet computer & 60 & 28,8 \\
CD/DVD player & 45 & 21,6 \\
Printer & 25 & 12 \\
Scanner & 19 & 9,1 \\
Projection & 7 & 3,4 \\
None of them & 2 & 1 \\
\hline
\end{tabular}

Participants were asked to indicate for how long they have been using ICT tools, and Table 4 reports data on duration of use. Table 4 shows that 38,9\% of the participants have been using computers for $8-11$ years, 59,6\% do not use tablet computers, and $42,3 \%$ have been using smartphones for 1-3 years and 41,8\% for 4-7 years. No participants reported having used a tablet computer for longer than 7 years.

Table 4. Duration of use of ICT tools

\begin{tabular}{lllllll}
\hline & Computer & \multicolumn{2}{c}{ Tablet Computer } & \multicolumn{2}{c}{ Smartphone } \\
Duration & $\mathrm{F}$ & $\mathbf{\%}$ & $\mathrm{F}$ & $\mathbf{\%}$ & $\mathrm{F}$ & \% \\
\hline Not use & 12 & 5,8 & 124 & $\mathbf{5 9 , 6}$ & 6 & 2,9 \\
Less than 1 year & 5 & 2,4 & 11 & 5,3 & 13 & 6,3 \\
1-3 years & 14 & 6,7 & 57 & 27,4 & 88 & $\mathbf{4 2 , 3}$ \\
4-7 years & 53 & 25,5 & 16 & 7,7 & 87 & 41,8 \\
8-11 years & 81 & $\mathbf{3 8 , 9}$ & 0 & 0 & 12 & 5,8 \\
More than 11 years & 43 & 20,7 & 0 & 0 & 2 & 1,0 \\
\hline
\end{tabular}

In addition to duration of use, participants were asked to indicate how frequently they use ICT tools in their daily lives (Table 5). Table 5 shows that smartphone is the ICT tool most frequently used by participants in their daily lives, with 78,4 reporting that they use smartphones on a daily basis. $66,3 \%$ stated that they do not use tablet computers in their daily lives at all. $25,5 \%$ of participants said they used a computer several days a week, and $24 \%$ said they used a computer several hours every day.

Table 5. Frequency of use of ICT in daily lives

\begin{tabular}{lllllll}
\hline & \multicolumn{2}{l}{ Computer } & \multicolumn{2}{c}{ Tablet Computer } & \multicolumn{2}{c}{ Smartphone } \\
Frequency & $\mathrm{F}$ & $\%$ & $\mathrm{~F}$ & $\mathbf{\%}$ & $\mathrm{F}$ & $\%$ \\
\hline Every day, continuously & 39 & 18,8 & 2 & 1,0 & 163 & $\mathbf{7 8 , 4}$ \\
Several hours every day & 50 & 24,0 & 16 & 7,7 & 32 & 15,4 \\
Several days a week & 53 & $\mathbf{2 5 , 5}$ & 20 & 9,6 & 5 & 2,4 \\
Several hours a week & 36 & 17,3 & 13 & 6,3 & 0 & 0 \\
Several hours a month & 19 & 9,1 & 19 & 9,1 & 2 & 1,0 \\
None & 11 & 5,3 & 138 & $\mathbf{6 6 , 3}$ & 6 & 2,9 \\
\hline
\end{tabular}

Participants were asked to indicate how frequently they use ICT for studying purposes (Table 6). Table 6 shows that $32,7 \%$ of participants reported using computers to study several days a week, whereas a large majority (79,3\%) said they did not use tablet computers for studying purposes at all. $78 \%$ of participants use smartphones every day in their daily lives (Table 5), whereas daily use of smartphones for studying purposes is reported only by $19,7 \%$ of participants (Table 6). 27,9\% of participants reported using smartphones for studying purposes several times a day, and 33,2\% said they did not use any digital materials for their studies at all. 
Table 6. Frequency of use of ICT for studying purposes

\begin{tabular}{lllllllll}
\hline & \multicolumn{2}{c}{ Computer } & \multicolumn{2}{c}{ Tablet Computer } & \multicolumn{2}{c}{ Smart Phone } & \multicolumn{2}{c}{ Digital Material } \\
Frequency & F & $\%$ & F & $\%$ & F & $\%$ & F & $\%$ \\
\hline Every day, continuously & 12 & 5,8 & 2 & 1,0 & 41 & 19,7 & 13 & 6,3 \\
Several hours every day & 18 & 8,7 & 3 & 1,4 & 28 & 13,5 & 22 & 10,6 \\
Several days a week & 68 & $\mathbf{3 2 , 7}$ & 16 & 7,7 & 58 & $\mathbf{2 7 , 9}$ & 35 & 16,8 \\
Several hours a week & 54 & 26,0 & 9 & 4,3 & 35 & 16,8 & 20 & 9,6 \\
Several hours a month & 49 & 23,6 & 13 & 6,3 & 27 & 13,0 & 49 & 23,6 \\
None & 7 & 3,4 & 165 & $\mathbf{7 9 , 3}$ & 19 & 9,1 & 69 & $\mathbf{3 3 , 2}$ \\
\hline
\end{tabular}

$92 \%$ of participants stated that they took a course on ICT tools, whereas $8 \%$ reported not having received any training on this subject. $80 \%$ of participants never used ICT tools to develop digital materials for special education, whereas $20 \%$ developed digital materials for special education using ICT tools.

\subsection{Results of the Factor Loading Analysis}

To examine construct validity of the scale, an Exploratory Factor Analysis (EFA) was conducted. Factor loadings for the variables that make up the Technology Acceptance Model were calculated. Results of the exploratory factor analysis of the variables, conducted using Varimax rotation, are reported in Table 7. None of the items on the questionnaire had a factor loading smaller than 0,500 .

Table 7. Factor loadings of the variables

\begin{tabular}{|c|c|c|c|c|}
\hline & \multicolumn{4}{|c|}{ Factors (Eigen Values $>1$ ) } \\
\hline & 1 & 2 & 3 & 4 \\
\hline PEU1 & ,124 & ,881 & ,087 &,- 057 \\
\hline PEU2 & 135 & ,894 & ,089 &,- 015 \\
\hline PEU3 & 091 & ,862 & ,095 &, 074 \\
\hline PEU4 & 254 & 697 & ,236 & ,097 \\
\hline PEU5 & ,132 & ,608 & ,073 & ,079 \\
\hline PEU6 & 285 & 689 &, 166 & 141 \\
\hline PU1 &, 767 & ,190 & ,211 & ,182 \\
\hline PU2 & ,780 & ,288 & ,269 & ,075 \\
\hline PU3 & 799 & 064 & 219 & ,273 \\
\hline PU4 & ,794 & ,211 & 225 & 204 \\
\hline PU5 &, 739 & 226 & 274 &, 133 \\
\hline PU6 &, 718 & ,229 &, 271 &, 244 \\
\hline SN1 & ,342 & ,190 & ,129 & ,765 \\
\hline SN2 & ,225 & 072 & 328 & ,642 \\
\hline SN3 & ,206 & 081 & 308 &, 833 \\
\hline BI1 & ,235 &, 142 & ,791 & ,316 \\
\hline $\mathrm{BI} 2$ & 213 & ,151 & ,876 & ,227 \\
\hline $\mathrm{BI} 3$ & 255 &, 170 & ,798 & ,246 \\
\hline BI4 & 296 & 188 & 847 & 192 \\
\hline BI5 & ,388 & 142 & ,697 & ,003 \\
\hline
\end{tabular}

\subsection{Results of the Structural Equation Model Analysis}

Hypotheses H1, H3, H4 and H5 were accepted, and hypothesis H2 was rejected on the basis of the SEM analysis conducted. Table 8 reports results of the model fit analysis in a comparative manner, path diagram is shown in Figure 2 , and Table 9 reports SEM results. Fit statistics commonly used in the literature, reference values to interpret these statistics, and values obtained from the model are reported in Table 8. In structural equation models, the ratio of chi-square $\left(\mathrm{X}^{2}\right)$ to degrees of freedom (df) $\left(\mathrm{X}^{2} / \mathrm{df}\right)$ should be lower than 3 (Schermelleh-Engel, Moosbrugger \& Müller, 2003). The obtained value of 2,49 is within acceptable limits. Root Mean Square Error of Approximation (RMSEA), Comparative Fit Index (CFI) and Tucker-Lewis Index (TLI) fit statistics are also within acceptable limits. 
Table 8. Fit criteria and model fit statistics

\begin{tabular}{llll}
\hline Fit Criteria & Recommended Value & Model & Reference \\
\hline $\mathrm{X}^{2}$ & $2 \mathrm{df}<\mathrm{X}^{2} \leq 3 \mathrm{df}$ & 401,01 & Schermelleh-Engel, Moosbrugger \& Müller (2003) \\
$\mathrm{df}$ & & 161 & \\
$\mathrm{X}^{2} / \mathrm{df}$ & 2,49 & Schermelleh-Engel, Moosbrugger \& Müller (2003) \\
$\mathrm{p}$ & & 0,00 & \\
$\mathrm{RMSEA}$ & $\leq 0,08$ & 0,08 & McDonald and Ho (2002), Schermelleh-Engel, \\
& & Moosbrugger \& Müller (2003) \\
CFI & $0,9 \leq \mathrm{CFI}$ & 0,93 & Klem (2000), McDonald and Ho (2002) \\
TLI & $0,9 \leq \mathrm{TLI}$ & 0,92 & Klem (2000), McDonald and Ho (2002) \\
\hline
\end{tabular}

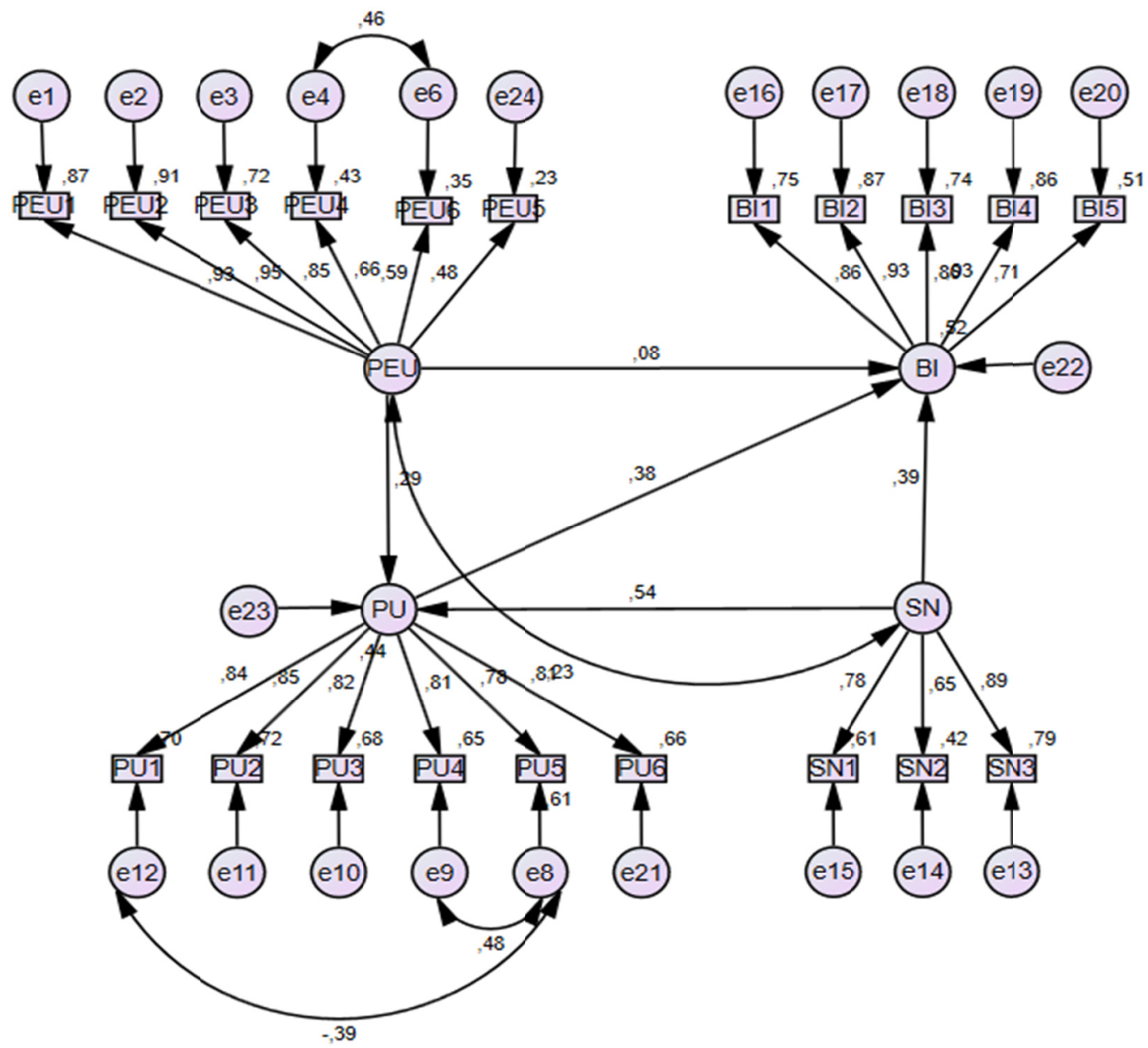

Figure 2. Structural Equation Model Path Diagram

As the structural equation model path diagram (Figure 2) shows, the variable of "perceived ease of use" (PEU) is measured by 6 items, but the two most important items are "It is easy for me to learn how to use ICT tools" (PEU1) with 93\%, and "It is easy for me to use ICT tools" (PEU2) with 95\%. The variable of "perceived usefulness" (PU) is also measured by 6 items, with the items having similar levels of influence varying between $85 \%$ and $78 \%$. The two items with the highest values are "Using ICT tools improves my course performance" (PU1) with 84\%, and "Using ICT tools allows me to conduct my courses more quickly" (PU2) with $85 \%$. The variable of behavioral intention (BI) is measured by 5 variables. Of those, the most important two are "It is a very good idea to use ICT tools in courses" (BI2) with 93\%, and "I would like ICT tools to be used in my classes" (BI4) with 93\%. The variable of subjective norms (SN) is measured by 3 items. The item "People I care about think that using ICT tools in my courses is a good idea" (SN3) has the highest effect on the variable with $89 \%$.

As the structural equation model path diagram (Figure 2) and the table of hypotheses (Table 9) show, opinions of people (SN) around pre-service special education teachers predict teachers' ideas about the usefulness (PU) of information and communication technologies with a significance level of 54\%. Subjective norms (SN) were found to predict teachers' behavioral intention (BI) to use ICT with a significance level of 39\%. Perceived Usefulness (PU) was found to predict teachers' behavioral intention (BI) to use ICT with a significance level of $38 \%$. Perceived ease of use (PEU) was found 
to predict teachers' ideas about the usefulness (PU) of information and communication technologies with a significance level of $29 \%$.

Table 9. Hypothesis rejection / acceptance table

\begin{tabular}{llllll}
\hline Hypothesis & Path & Direction Coefficient Values & T value & P & Accept /Reject \\
\hline H1 & PEU $\rightarrow$ PU &, 29 & 4,51 & $<, 001$ & Accepted \\
H2 & PEU $\rightarrow$ BI &, 08 & 1,28 &, 202 & Rejected \\
H3 & PU $\rightarrow$ BI &, 38 & 4,59 & $<, 001$ & Accepted \\
H4 & SN $\rightarrow$ PU &, 54 & 7,23 & $<, 001$ & Accepted \\
H5 & SN $\rightarrow$ BI &, 39 & 4,86 & $<, 001$ & Accepted \\
\hline
\end{tabular}

Results mostly supported the Technology Acceptance Model (TAM), with one exception: the theoretical expectation that perceived ease of use (PEU) would affect behavioral intention (BI) to use technology was not empirically supported (Table 9).

\section{Discussion}

Studies on the effects of information and communication technologies show that their use improves instructors' effectiveness and efficiency when teaching (Kirkup \& Kirkwood, 2005). New technologies strengthen cooperation and communication in education and training, and increase the flexibility and convenience of educational activities. The technology supported learning methods can be better adapted for students if teachers' and students' reactions to technology supported learning systems are understood well (Turan \& Colakoglu, 2008). To utilize the full potential of information and communication technologies, complementary and descriptive studies are needed.

This study aimed to identify the factors that affect an individual's decision to accept and use information and communication technologies, using the framework of TAM and working with pre-service special education teachers. First, data were collected on the duration and frequency of use of information and communication technologies by pre-service special education teachers. It was found that pre-service special education teachers used ICT tools frequently in their daily lives and a large majority of participants received training on ICT tools, but the duration and frequency of use for studying purposes were much lower. The findings of this study can be important for identifying the factors behind this behavior and taking necessary measures.

Special education teachers' perceptions of usefulness (PU) of information and communication technologies, as well as opinions of people (SN) they care about regarding use of technology, shape their behavioral intentions (BI) towards information and communication technologies. In addition, special education teachers' perceptions regarding the ease of use (PEU) of information and communication technologies, and opinions of people (SN) they care about regarding use of technology, predict their perceptions of usefulness (PU) of these technologies. Perceived ease of use (PEU) was not found to have a statistically significant effect on behavioral intention (BI). In another study that used technology acceptance model, perceived usefulness was found as a dominant factor affecting assistive technology usage (Nam et al, 2013).

Proper and effective use of technology by special education professionals goes hand in hand with their frequency of use of ICT tools in class, and competency in ICT supported education (Flanagan, Bouck \& Richardson, 2013). If pre-service teachers make more active use of ICT tools for studying purposes during their college education, this would help them make more use of technology after graduation when they conduct sessions with special education students. This is because pre-service teachers' intention to accept and use ICT would improve if they were introduced to technology-supported practices in the courses they take and found these practices to be useful and effective (Avcu $\&$ Gokdas, 2012). Therefore, during their university education, pre-service teachers should be provided periodic training regarding the effects of ICT practices on the learning/teaching process, and they should be encouraged to participate in these programs.

\section{References}

Avcu, D. U., \& Gokdas, I. (2012). Acceptance and Usage Intentions Related to Information and Communication Technologies of Second Cycle Primary School Teachers, Journal of Educational Sciences, 3(1), 42-59.

Bertini, E. S., \& Kimani, S. (2003). Mobile devices: opportunities for users with special needs. Mobile HCI. In L. Chittaro (Ed.). Lecture Notes of Computer Science, 2795, 486-491. https:/doi.org/10.1007/978-3-540-45233-1_52

Davis, F. D. (1989). Perceived usefulness, perceived ease of use, and user acceptance of information technology. MIS Quarterly, 13(3), 319-340. https:/doi.org/10.2307/249008

Derer, K., Polsgrove, L., \& Rieth, H. (1996). A survey of assistive technology applications in schools and recommendations for practice. Journal of Special Education Technology, 13, 62-80.

Edwards, B. J., Blackhurst, A. E., \& Koorland, M. A. (1995). Computer-assisted constant time delay prompting to teach 
abbreviation spelling to adolescents with mild learning disabilities. Journal of Special Education Technology, 12, $301-311$.

Fernández-Lopez, Á, Rodríguez-Fórtiz, M. J., Rodríguez-Almendros, M. L., \& Martínez-Segura, M. J. (2013). Mobile learning technology based on iOS devices to support individuals with special education need. Computers \& Education, 61(0), 77-90. http://dx.doi.org/10.1016/j.compedu.2012.09.014

Fishbein, M., \& Ajzen, I. (1975). Belief, Attitude, Intention and Behavior: An Introduction to Theory and Research. Reading, MA: Addison-Wesley.

Flanagan, S., Bouck, E. C., \& Richardson, J. (2013). Middle school special education teachers' perceptions and use of assistive technology in literacy instruction. Assistive Technology, 25(1), 24-30. https:/doi.org/10.1080/10400435.2012.682697

Hair, J. F., Jr., Black, W. C., Babin, B. J., \& Anderson, R. E. (2005). Multivariate data analysis (6th ed.). NY: Prentice Hall.

Hu, P. J., Clark, T. H. K., \& Ma, W. W. (2003). Examining technology acceptence by school teachers: a logtudial study. Information \& Management, 41(2), 227-241. https:/doi.org/10.1016/S0378-7206(03)00050-8

Kirkup, G., \& Kirkwood, A. (2005). Information and communications technologies (ICT) in higher education teaching - a tale of Gradualism rather than revolution. Learning, Media and Technology, 30(2), 185-199.

Klem, L. (2000). Structural equation modeling.

Kline, R. B. (2005). Principles and practice of structural equation modeling (2nd ed.). Guilford Press, New York.

Lee, Y., \& Vega, L. A. (2005). Perceived knowledge, attitudes, and challenges of AT use in special education. Journal of Special Education Technology, 20, 60-63.

Ludlow, B. L. (2001). Technology and teacher education in special education: Disaster or deliverance? Teacher Education and Special Education, 24, 143-163.

Ma, W. W., Anderson, R., \& Streith, K. O. (2005). Examining user acceptance of computer technology: an empirical study of student teachers, Journal of Computer Assisted Learning, 21, 387-395.

Martin, S. S. (2004). A sampling of activities used in special education teacher preparation coursework: Meeting the standards. In Proceedings of Society for Information Technology and Teacher Education International Conference 2004(1), 4930-4935. Norfolk, VA: AACE.

McDonald, R. P., \& Ho, M. H. R. (2002). Principles and practice in reporting structural equation analyses. Psychological methods, 7(1), 64. https:/doi.org/10.1037/1082-989X.7.1.64

Michaels, C. A., \& McDermott, J. (2003). Assistive technology integration in special education teacher preparation: Program coordinators' perceptions of current attainment and importance. Journal of Special Education Technology, 18, 29-41.

Nam, C. S., Bahn, S., \& Lee, R. (2013). Acceptance of assistive technology by special education teachers: A structural equation model approach. International Journal of Human-Computer Interaction, 29(5), 365-377. https:/doi.org/10.1080/10447318.2012.711990

Schermelleh-Engel, K., Moosbrugger, H., \& Müller, H. (2003). Evaluating the fit of structural equation models: Tests of significance and descriptive goodness-of-fit measures. Methods of psychological research online, 8(2), 23-74.

Teo, T. (2009). Evaluating the intention to use technology among student teachers: A structural equation modeling approach. International Journal of Technology in Teaching and Learning, 5(2), 106-118.

Teo, T. (2011). Factors influencing teachers' intention to use technology: Model development and test. Computers \& Education, 57(4), 2432-2440. https:/doi.org/10.1016/j.compedu.2011.06.008

Turan, A. H., \& Çolakoğlu, B. E. (2008). Faculty's acceptance and use of technology in higher education: an empirical assessment at Adnan Menderes University. Journal of Dogus University, 9(1), 106-121.

Yee, H. S. S. (2012). Mobile technology for children with autism spectrum disorder: Major trends and issues. 2012 IEEE Symposium on E-Learning, E-Management and E-Services (IS3e), 1-5.

https:/doi.org/10.1109/IS3e.2012.6414954

\section{(cc) Br}

This work is licensed under a Creative Commons Attribution 3.0 License. 